\title{
How is contraction not possible here?
}

\author{
Marjorie $\mathrm{Pak}^{*}$ \\ LSA Annual Meeting, Portland, January 8-11, 2015
}

1. Another kind of how-question. Typically, how-questions are assumed to query manner or instrument (1a)-(1b). However, English how-questions can also have a very different, largely unnoticed interpretation: they can be used (rhetorically) to express extreme surprise that the proposition under how holds at all (1c). I will refer to these 'propositional' how-questions as $P H Q s$, and to the more familiar manner and instrument how-questions collectively as MHQs.

(1) How did John fix that chair?
a. Very slowly and carefully.
(manner, MHQ)
b. With a hammer.
(instrument, MHQ)
c. I know! I didn't think he could fix anything!
(propositional, PHQ)

While many how-questions, like (1), are ambiguous between MHQ and PHQ readings, MHQs and PHQs are distinguished by at least three properties. First, PHQs can be used with all kinds of stative predicates, while MHQs cannot - presumably because manner/instrument modifiers are incompatible with states (Smith 1991:ch3, Katz 2000). For example, while fall asleep in (2) denotes a change of state, be asleep in (3) denotes a simple state (reinforced by the adverb still (Katz 2000)). Correspondingly, the MHQ reading is available in (2) but not in (3). More examples of unambiguous PHQs with statives are given in (4).

(2) How did Sarah fall asleep?

a. By counting backwards slowly. (MHQ) b. I know; she was so wired at bedtime! (PHQ)

(3) How is Sarah still asleep?

a. \#By keeping her blinds closed. (MHQ) b. I know; it's been ten hours now! (PHQ)

(4) a. How is Chili's still open? (It's 2:00a.m.!)

b. How do you hate this song? (It's got such great lyrics!)

c. How has it already snowed six times? (It's only October!)

Second, PHQs are fully compatible with sentential negation, showing none of the weak-island effects induced by negation in MHQs (Abrusán 2008, Ross 1984, Kuno \& Takami 1997, etc.):

(5) How did John not fix that chair?
a. \#With a hammer. / \#Carefully.
b. I know! It looked like such a simple job!
(\#MHQ)
(PHQ)

Oddly, however, while PHQs freely allow negation, they resist Neg-contraction to n't:

(6) a. How \{ is Chili's not / ?*isn't Chili's $\}$ open yet?

b. How $\{$ do you not / ?*don't you $\}$ love this song?

c. How $\{$ has it not / ?*hasn't it $\}$ snowed at all this winter?

Some speakers that I have consulted reject sentences like (6) outright; others find them marginally acceptable. All have agreed, however, that there is a clear contrast in acceptability between the how-questions in (6) and the why-questions in (7), where Neg-contraction is fine:

\footnotetext{
* Thanks to David Embick, Tony Kroch, and my anonymous LSA reviewers for helpful comments and discussion. All errors are of course my own. Author: Marjorie Pak, Emory University (mgpak@emory.edu).
} 
(7) a. Why isn't Chili's open yet?

b. Why don't you love this song?

c. Why hasn't it snowed at all this winter?

The contrast between (5) and (6) (and between (6) and (7)) presents an interesting puzzle: Given that there is no problem with negation per se in PHQs, why should it matter if Neg is reduced to $n$ 't or spelled out as not? I offer the following explanation: ${ }^{1}$

(8) Proposal: The problem arises when Neg raises to C. Raising allows Neg to undesirably scope over a VERUM operator in C that is responsible for the PHQ's unique semantics.

2. Analysis. Compare the two structures in (9). In the MHQ in (9)a, how is merged as a low vP adjunct (Katz 2000; Thomason \& Stalnaker 1973) and moves to Spec,CP. In the PHQ in (9)b, on the other hand, how is initially merged in Spec,CP - i.e., PHQ-how takes scope over the entire proposition that follows, with no missing arguments or other gaps. Correspondingly, PHQs are immune to negative-island effects (5), which (by hypothesis) arise only when Neg c-commands a wh-trace (Ross 1984, Kuno \& Takami 1997). Similarly, PHQs (unlike MHQs) do not allow family-of-questions readings (10), which (by hypothesis) arise when a universal quantifier c-commands a wh-trace (May 1985).

(9)

a. Manner/instrument how-q (MHQ)

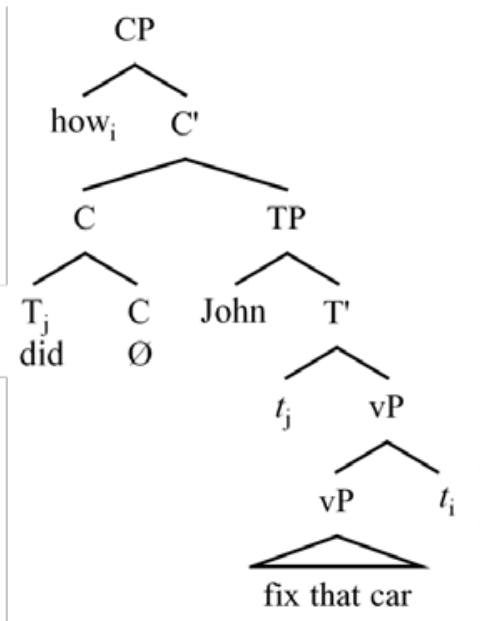

b. Propositional how-q (PHQ)

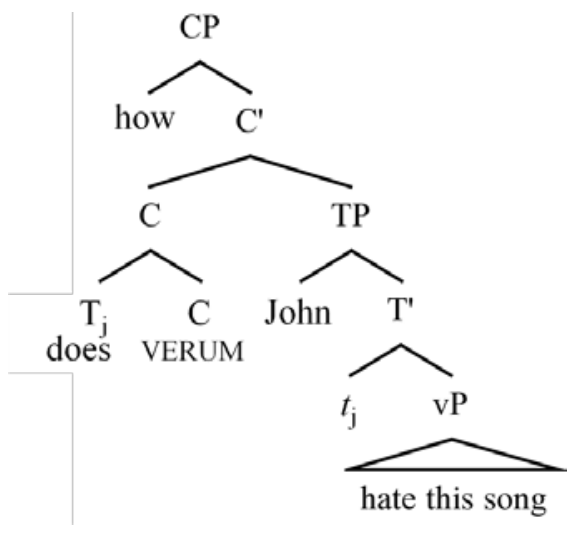

(10) a. Q: How did everyone [vp get to sleep how $\left.\mathrm{w}_{\mathrm{i}}\right]$ ?

(MHQ)

A: John counted sheep, Mary listened to soft music, Sam drank warm milk...

b. Q: How is [тр everyone still asleep]?

(PHQ)

A: I know! I thought at least one person would still be awake.

A second difference between the two structures in (9) is that the PHQ has a covert semantic operator, VERUM, in C. Recall that, in addition to acknowledging the truth of the proposition under how, a PHQ also expresses extreme surprise at the truth of the proposition under how. A PHQ is arguably an attempt to resolve an internal epistemic conflict (cf. Romero \& Han 2004): the speaker previously believed that $p$ was nearly impossible, and now must recognize the

\footnotetext{
1 There is another type of how-question, distinct from both PHQs and MHQs, which I have provisionally coined the 'metalinguistic how-q': e.g. How is John a good husband? (= 'How can you say that John is a good husband?'). These questions are interpreted as challenges to another speaker's use of a word/phrase (here, a good husband); crucially, unlike PHQs they do not presuppose the proposition under how. I leave their analysis for future work.
} 
certainty of $p$. The implicit question is 'What caused such an unlikely reversal?' - a question with an existentialist flavor that usually ends up being interpreted rhetorically.

I propose that the PHQ's interpretation comes about via the combination of how (propositional how) in Spec,CP and a covert VERUM operator in C.

(11) $\left[\left[\text { how }_{\mathrm{P}}\right]\right]^{2}=\lambda \mathrm{r}$. What is the $q$ such that $\operatorname{CAUSE}(q, r)$ ? (Tsai 2008)

(12) $[[$ VERUM] $]=\lambda$. It is for-sure that $p$ should be added to CG (Romero \& Han 2004)

VERUM, according to Romero \& Han 2004, is a conversational epistemic operator that asserts the speaker's certainty that a proposition should be added to the Common Ground (CG) (similar to really in Sarah really is still asleep). Suppose that the purpose of VERUM in the PHQ is to rule out the possibility that there is some mistake about the truth of $p$. This could be the source of the 'extreme surprise' interpretation of a PHQ: The addition of VERUM to $p$ yields an implicature that $p$ is particularly unlikely or hard to believe (otherwise VERUM would be unnecessary information, per Grice’s (1975) Quantity-2 maxim).

(13) $\left[\left[\right.\right.$ how $_{\mathrm{P}}$ VERUM $\left.\left.p\right]\right]=$ 'What is the $q$ such that $q$ caused it to be for-sure that $p$ should be added to CG?'

Now let's return to the question raised in $\S 1$ : Why is Neg-contraction dispreferred in negative PHQs but fine in negative why-questions?

(14) a. ?* How doesn't John love this song?

b. $c f$. Why doesn't John love this song?

I assume that questions with Neg-contraction are derived in two steps:

(15) a. STEP 1 (Syntax): Neg raises to $\mathrm{T}$ and then to $\mathrm{C}$ by syntactic head-movement: [ср why [c [T does $\left.\mathbf{N e g}_{\mathbf{j}}\right]_{\mathrm{i}}$ ] [TP John [T does $\left.\mathbf{N e g}_{\mathbf{j}}\right]_{\mathrm{i}}$ [NegP $\mathbf{N e g}_{\mathbf{j}}$ [vP love this song ]]]]

b. STEP 2 (PF): Neg is spelled out as $n$ 't by a Vocabulary Insertion (allomorphy) rule: $[+\mathrm{NEG}] \leftrightarrow n^{\prime} t / \mathrm{X}^{+}+$(within the same M-word (Embick 2010)) $\leftrightarrow$ not / elsewhere

Since PHQs have VERUM in C, a problem arises at Step 1 of this derivation: The raising and incorporation of Neg into $\mathrm{C}$ enables Neg to take scope over VERUM. The resulting complex head is ambiguous between the intended reading (15)a ('How is it for-sure that John does not love this song?’) and the unintended (15)b (*‘How is it not for-sure that John loves this song?’).

(16) a. Intended: how $_{\mathrm{P}}>\mathrm{VERUM}>\mathrm{NEG}>p$

'What is the $q$ such that $q$ causes it to be for-sure that $\sim p$ should be added to CG?'

b. Unintended: * how $_{\mathrm{p}}>\mathrm{NEG}>\mathrm{VERUM}>p$

'What is the $q$ such that $q$ causes it not to be for-sure that $p$ should be added to CG?'

If Neg is left in situ below $\mathrm{C}_{\text {[VERUM] }}$, this ambiguity is avoided. Neg is then spelled out as not by the allomorphy rule in (15)b.

(17) [CP how [C [T does $\left._{\mathrm{i}}\right]$ VERUM] [TP John $t_{\mathrm{i}}$ [NegP not [ ${ }_{\mathrm{vP}}$ love this song $\left.\left.]\right]\right]$ VERUM $>$ NEG

3. Predictions and implications. If my analysis is on the right track, then we should expect Neg-contraction to be fine in a PHQ as long as Neg stays below C. We can test this prediction by

\footnotetext{
${ }^{2}$ I distinguish how $(\mathrm{PHQ}$ how) from how (MHQ how), which combines with predicates rather than propositions.
} 
embedding a PHQ under a predicate like wonder or want to know, since T does not raise to C in indirect questions in standard English. As predicted, spellout as $n$ 't is fully grammatical:

(18) I want to know [ср how [с VERUM] [тр John [т does [ $n$ ’ $\left.t_{\mathrm{i}}\right]$ ] [NegP $t_{\mathrm{i}}$ [vp love this song ]]]]

A second prediction made by this account is that Neg-to-C raising, and subsequent spellout as $n$ 't, should be fine in any wh-question without VERUM (or any other semantic operator) in C. We can test this prediction by revisiting manner how-questions (MHQs), which do not have VERUM in C (9). Recall that negative MHQs are subjected to weak-island effects (19). But as noted by Kroch 1989, these weak-island effects can be removed by contextual conditions (20):
A. How did John not fix that chair?
B. \# With a hammer.

(20) John tried everything! The real question is: how didn't he fix the chair?

Notice that Neg-contraction is grammatical in (20). This is just what we expect under the current analysis, since there is no VERUM to inhibit Neg-to-C raising in MHQs.

The idea that Neg-to-C raising can result in scopal interactions with VERUM is central to Romero \& Han's (2004) account of English negative yes/no questions. According to Romero \& Han, Isn't there a vegetarian restaurant around here? can be used either in a context where the speaker is biased towards believing that there is a vegetarian restaurant nearby $(\mathrm{Q}>\mathrm{NEG}>$ VERUM $>p$ ), or in a context where the speaker is biased towards believing that there is not a vegetarian restaurant nearby $(\mathrm{Q}>\mathrm{VERUM}>\mathrm{NEG}>p$ ) (see Ladd 1981). I am proposing that the PHQ is another context where VERUM and Neg potentially interact - but in the PHQ, VERUM has an inhibitory effect on Neg-to-C raising because the resulting ambiguity is undesirable.

The current analysis is also very much in line with previous observations that $n$ ' $t$ is fundamentally different from 'other clitics' like ' $l l$ and 've; for example, $n$ 't cannot attach outside 'll or 've (*we'ven't), arbitrarily fails to attach to certain hosts (*amn't), and triggers unpredictable phonological effects (/du/+n’t $\rightarrow$ /dont/) (Zwicky \& Pullum 1983). Crucially, I have argued that $n$ 't attaches to its host by syntactic head-movement (Step 1 from (15)) rather than by local rebracketing in PF (like 'll and 've (Embick \& Noyer 2001, Mackenzie 2012)). Given that $n$ 't is syntactically derived, its semantic effects seen here are unsurprising.

\section{References}

Abrusán, Márta. 2008. A semantic analysis of negative islands with manner questions. Proceedings of SuB12, 1-16. Collins, Chris. 1991. Why and how come. MIT Working Papers in Linguistics 15, 31-45.

Embick, David \& Noyer, Rolf. 2001. Movement operations after syntax. Linguistic Inquiry 32, 555-595.

Embick, David. 2010. Localism versus globalism in morphology and phonology. Cambridge, MA: MIT Press.

Grice, Paul. 1975. Logic and conversation. Syntax and semantics 3, 41-58.

Han, Chung-hye \& Siegel, Laura. 1996. NPI licensing in adjunct WH-questions. Proceedings of BLS 22, $147-158$.

Katz, Graham. 2000. A semantic account of the stative adverb gap. ZAS Papers in Linguistics 17, 135-151.

Kroch, Anthony, 1989. Amount quantification, referentiality, and long wh-movement. Ms., Univ. of Pennsylvania.

Kuno, Susumu \& Takami, Ken-ichi. 1997. Remarks on negative islands. Linguistic Inquiry 28(4), 553-576.

Ladd, Robert D. 1981. A first look at the semantics and pragmatics of negative questions and tag questions. Papers from the $17^{\text {th }}$ Regional Meeting of the Chicago Linguistic Society, 164-171.

Mackenzie, Laurel. 2012. Locating variation above the phonology. Doctoral dissertation, Univ. of Pennsylvania.

May, Robert. 1985. Logical form: its structure and derivation. Cambridge, MA: MIT Press.

Romero, Maribel \& Han, Chung-hye. 2004. On negative yes/no questions. Linguistics and Philosophy 27, 609-658.

Ross, Haj. 1984. Inner islands. Proceedings of BLS 10, 258-265.

Smith, Carlota S. 1991. The parameter of aspect. Dordrecht: Kluwer.

Thomason, R. H. \& Stalnaker, R. C. 1973. A semantic theory of adverbs. Linguistic Inquiry 4(2), 195-220.

Tsai, Wei-Tien Dylan. 2008. Left periphery and how-why alternations. Journal of East Asian Linguistics 17, 83-115. Zwicky, Arnold M. \& Pullum, Geoffrey K. 1983. Cliticization vs. inflection: English N’T. Language 59, 502-513. 